\title{
Influence of the amount of inflowing wastewater on concentrations of pollutions contained in the wastewater in the Nowy Targ sewerage system
}

\author{
Elwira Nowobilska-Majewska ${ }^{1}$, and Piotr Bugajski ${ }^{1,{ }^{*}}$ \\ ${ }^{1}$ Department of Sanitary Engineering and Water Management University of Agriculture in Kraków, Mickiewicza 24/28, 30-059 \\ Kraków, Poland
}

\begin{abstract}
This study presents the results of the analysis concerning the influence of the amount of inflowing wastewater on concentrations of organic and biogenic pollutants, as well as chromium ions in wastewater flowing into the collective sewage treatment plant in Nowy Targ. The research was carried out in 2016 and 2017, where in the period of 24 months a total number of 87 wastewater samples were collected in order to determine the concentration of the analyzed pollution indicators. During this period, the average daily inflow of wastewater to the sewage treatment plant was also analyzed. Based on the analysis of linear correlation, it was stated that there is a high dependence of concentrations of organic and biogenic pollutants on the amount of inflowing raw wastewater. Furthermore, it was found that there is an average dependence of chromium ion concentrations in raw wastewater on the amount of inflowing wastewater. In order to minimize the high variability of the concentration of pollutants in raw wastewater, it is recommended to reconstruct the sewerage system from the combined sewer system to the distribution system. Additionally, it is recommended to monitor the sewerage network in order to eliminate illegal inflows of rainwater and industrial wastewater from furrier's production facility.
\end{abstract}

\section{Introduction}

The operation of a wastewater treatment plants is a complicated process, which depends on many factors, including factors independent of the facility's operator. These factors include accidental and infiltration waters, influence of external temperature on wastewater temperature in a biological reactor or illegal inflow of industrial wastewater [1-6]. Uneven inflow of wastewater, as well as uneven concentrations of pollutants contained in it, have a negative impact on the processes of both mechanical and biological sewage treatment [7-9]. In order to avoid these types of undesirable phenomena, sewerage systems should be protected from illegal introduction of accidental waters (rainwater) and industrial wastewater.The purpose of this work was to determine the influence of the amount of inflowing wastewater on the change in the concentration of organic and biogenic pollutants and chromium ions in wastewater flowing into the wastewater treatment plant in Nowy Targ.

\section{Material and methods}

The research was carried out in 2016 and 2017, where in the period of 24 months, a total number of 87 sewage samples were collected. Then, the samples were subjected to physical-chemical analysis in accordance with the applicable reference methods. Raw sewage samples were taken from inflow channel by an autosampler, which was programmed in relation to the flow rate of the sewage. In addition, the measurement covered the amount of inflowing wastewater in the day, in which sewage samples were collected. In the analytical part of the study, a statistical analysis was carried out along with the calculation of Pearson's linear correlation coefficient in order to analyze (statistically) the impact of the amount of inflowing sewage $Q_{\text {d.śr. }}$ on concentrations/values: $\mathrm{BOD}_{5}, \mathrm{COD}$, total nitrogen, total phosphorus and chromium ions in raw wastewater. Samples of wastewater were subjected to the physicalchemical analysis in accordance with reference methods set out in the applicable legal acts.

- $\mathrm{BOD}_{5}$ - PN-EN1899-1:2002;PNEN25814:1999,

- $\mathrm{COD}_{\mathrm{cr}}$ - PN-ISO 15705:2005,

- Total nitrogen - KJ-I-5.4-186,

- Total phosphorus - PN-EN ISO6878:2006 + Ap1:2010 + Ap2010,

- Chromium - EN ISO11083 DIN 38405-D24.

\subsection{Characteristics of the sewerage system}

The sewerage system in Nowy Targ has a length of 42.4 $\mathrm{km}$, including $1.7 \mathrm{~km}$ of pressure pipes. The sewerage

\footnotetext{
* Corresponding author: p.bugajski@urk.edu.pl
} 
network is made of PVC and stoneware pipes with DN diameters from 200 to $400 \mathrm{~mm}$. Currently residents use this sewerage system 47537 residents. Additionally, 60 legally operated furrier's production facility, from which industrial wastewater is discharged, are connected to the sewage system. Household sewage and industrial wastewater flow into a collective mechanical and biological sewage treatment plant with a planned capacity (Qsr.d.) of $21000 \mathrm{~m}^{3} \cdot \mathrm{d}^{-1}$ and PE (population equivalent $)=116000$ residents.

\section{Results}

Based on the performed analysis concerning the amount of wastewater flowing into the sewage treatment plant in Nowy Targ, it was found that in 2016 the average daily wastewater inflow was $13810.9 \mathrm{~m}^{3} \cdot \mathrm{d}^{-1}$ (the median was $\left.12930.0 \mathrm{~m}^{3} \cdot \mathrm{d}^{-1}\right)$. The fluctuations of the average daily inflow ranged from 10552 to $21683 \mathrm{~m}^{3} \cdot \mathrm{d}^{-1}$. Based on the calculated unevenness coefficient $(\mathrm{Cv}=0.20)$, it was stated that the inflow of wastewater to the sewage treatment plant in Nowy Targ in 2016 was characterized by medium diversity [10].

In 2017, the average daily inflow of wastewater amounted to $14997.8 \mathrm{~m}^{3} \cdot \mathrm{d}^{-1}$ (the median was 14397.5 $\mathrm{m}^{3} \cdot \mathrm{d}^{-1}$ ) and it was higher compared to the previous year by $1186.9 \mathrm{~m}^{3} \cdot \mathrm{d}^{-1}$. Fluctuations in the average daily inflow ranged from 9835 to $21100 \mathrm{~m}^{3} \cdot \mathrm{d}^{-1}$. The unevenness coefficient for the average daily inflow of wastewater in 2017 was $\mathrm{Cv}=0.17$ and it was (according to the scale [10]) at the level of small diversity.

In the next part of the analysis, the influence of the amount of inflowing wastewater on the variability of the concentration of pollutants contained in it was determined on the basis of the Pearson's linear correlation. Characteristic values of the analyzed indicators are presented in Table 1.

Table 1. The characteristic values of the analyzed indicators in raw wastewater.

\begin{tabular}{|c|c|c|c|c|c|c|}
\hline Statistics & Unit & $\mathrm{BOD}_{5}$ & $\mathrm{COD}_{\mathrm{cr}}$ & $\mathrm{N}_{\text {tot }}$ & $P_{\text {tot }}$ & $\mathrm{Cr}$ \\
\hline \multicolumn{7}{|c|}{2016} \\
\hline Min. & \multirow{5}{*}{ למ } & 206.5 & 640 & 50.58 & 6.67 & 2.5 \\
\hline Max. & & 935 & 3074 & 165.9 & 30.7 & 18.5 \\
\hline Average & & 533.4 & 1689.7 & 103.6 & 16.8 & 8.2 \\
\hline Median & & 546.5 & 1576.0 & 97.2 & 16.7 & 7.1 \\
\hline $\begin{array}{l}\text { Deviat. } \\
\text { stand. }\end{array}$ & & 157.9 & 602.9 & 28.1 & 4.3 & 3.9 \\
\hline $\begin{array}{l}\text { Coeffic. } \\
\text { of variat. }\end{array}$ & - & 0.30 & 0.36 & 0.27 & 0.26 & 0.48 \\
\hline \multicolumn{7}{|c|}{2017} \\
\hline Min. & \multirow{5}{*}{ למ } & 278.8 & 653.1 & 52.7 & 5.42 & 7.2 \\
\hline Max. & & 760 & 2470 & 161.8 & 51.8 & 6.4 \\
\hline Average & & 504.8 & 1567.0 & 107.4 & 18.9 & 2.1 \\
\hline Median & & 482.2 & 1518.9 & 104.9 & 17.7 & 20.9 \\
\hline $\begin{array}{l}\text { Deviat. } \\
\text { stand. }\end{array}$ & & 128.8 & 471.3 & 31.1 & 9.3 & 3.7 \\
\hline $\begin{array}{l}\text { Coeffic. } \\
\text { of variat. }\end{array}$ & - & 0.26 & 0.30 & 0.29 & 0.49 & 0.52 \\
\hline
\end{tabular}

In each of the analyzed cases, the average daily inflow of wastewater $\left(Q_{\text {sr.d. }}\right)$ was the independent variable, while the dependent variable was the concentration of a certain indicator in the inflowing wastewater. The correlation level for all analyzed correlations was determined on the basis of the Stanisz's scale [11]. Based on the analysis of correlations, it was found that in 2016 (in the case of inflow/BOD dependence), the correlation coefficient was $r_{x, y}=-0.60$ and in 2017 was $r_{x, y}=-0.68$. Coefficient of determination $\mathrm{R}^{2}$ informs that the presented regression model in 2016 describes $35.43 \%$ and in 2017 it describes $46.19 \%$ of observations. In both analyzed years, the correlation of the inflow/BOD ${ }_{5}$ dependence was at a high level (Figure $1)$.
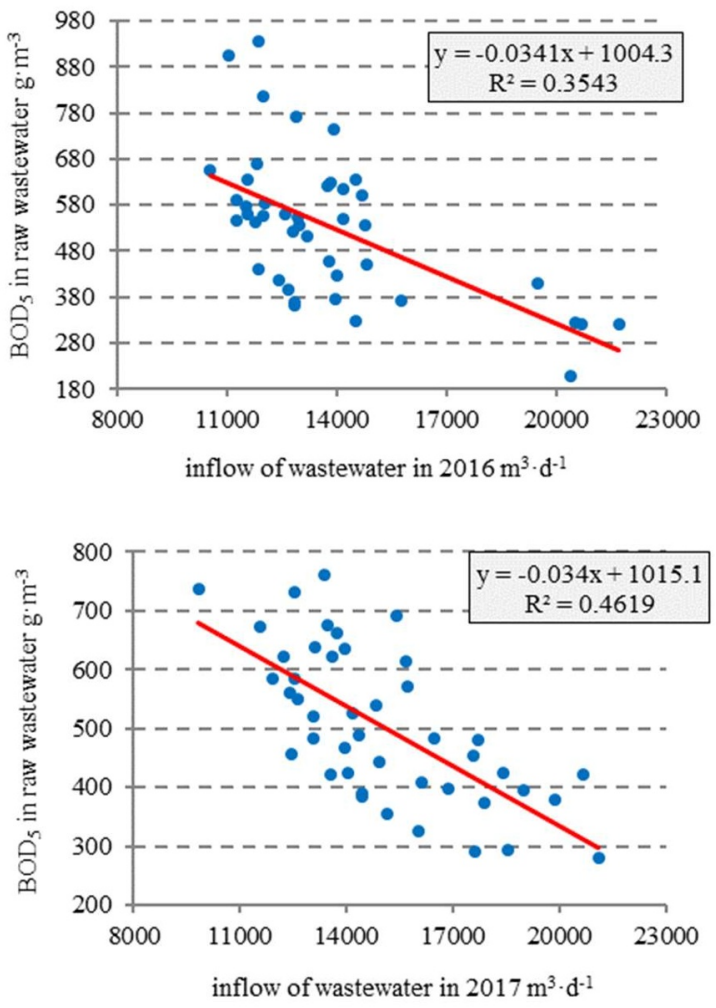

Fig. 1. The influence of the amount of inflow wastewater on BOD5 value in raw wastewater in 2016 and 2017.

In 2016, the correlation coefficient for the inflow/COD dependence was $r_{x, y}=-0.51$, and in 2017 was $r_{x, y}=-0.52$. Despite the fact that this dependence was lower than the previous one, according to the adopted scale - it is defined as high (Figure 2). In both analyzed years $\mathrm{R}^{2}$ coefficient of determination was similar and indicated that the described regression model describes $26.11 \%$ and $26.65 \%$ of observations, respectively.

In the case of the influence of the amount of inflowing wastewater on changes in biogenic pollutant concentrations, it was found that in 2016 the correlation coefficient of inflow $/ \mathrm{N}_{\mathrm{og}}$ dependence was $\mathrm{r}_{\mathrm{x}, \mathrm{y}}=-0.64$ and in 2017 was $r_{x, y}=-0.61$ (Figure 3). In this case the coefficient of determination $\mathrm{R}^{2}$ indicates that the influence of the amount of inflowing sewage explains 
$41.6 \%$ in 2016 and $36.9 \%$ in 2017 the variation of the concentration of total nitrogen in inflowing sewage.
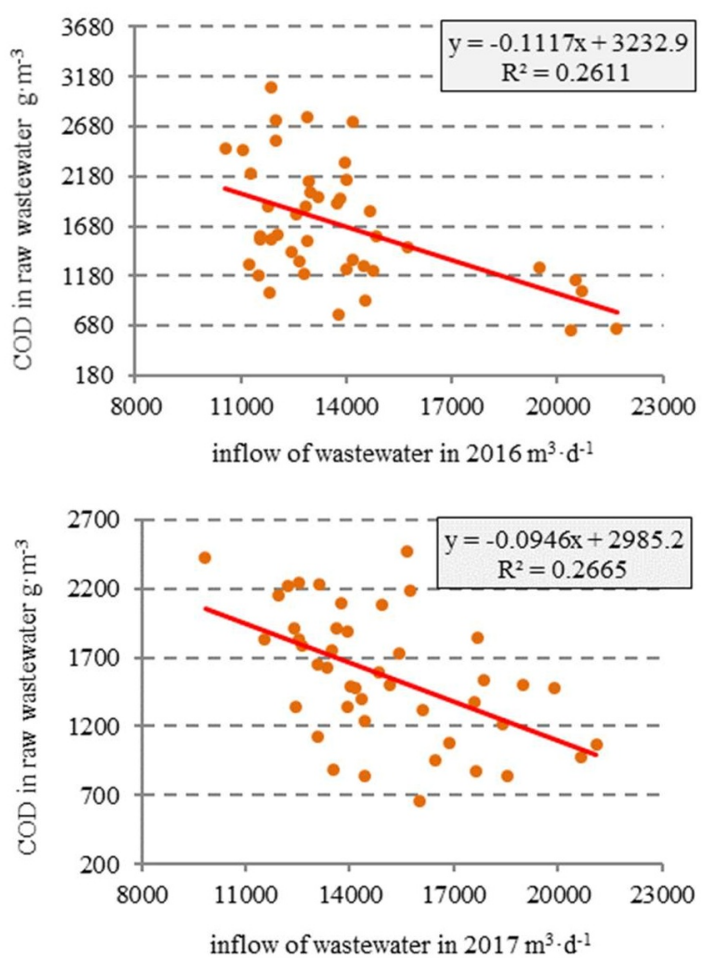

Fig. 2. The influence of the amount of inflow wastewater on COD value in raw wastewater in 2016 and 2017.
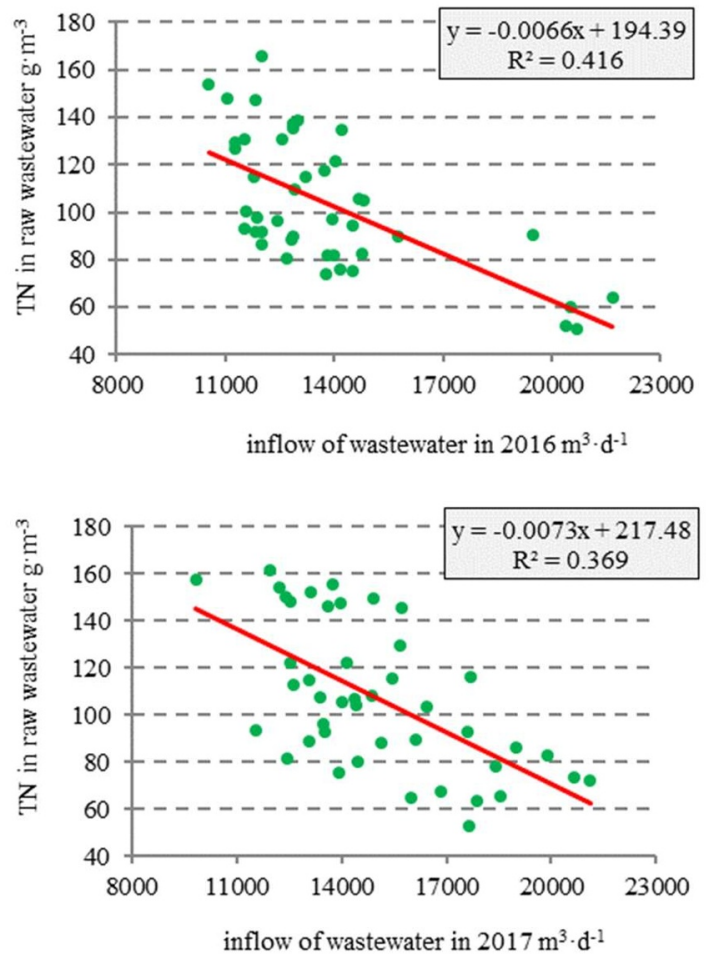

Fig. 3. The influence of the amount of inflow wastewater on Total Nitrogen value in raw wastewater in 2016 and 2017.
In 2016, the correlation coefficient for the inflow $/ \mathrm{P}_{\mathrm{og}}$ dependence was $r_{x, y}=-0.58$ and in 2017 was $r_{x, y}=-0.63$ (Figure 4). In the case of dependence, the coefficient of determination $\mathrm{R}^{2}$ indicates that the influence of the amount of incoming sewage explains $34.04 \%$ in 2016 and $39.18 \%$ in 2017 the variation in the concentration of total phosphorus in incoming effluents.
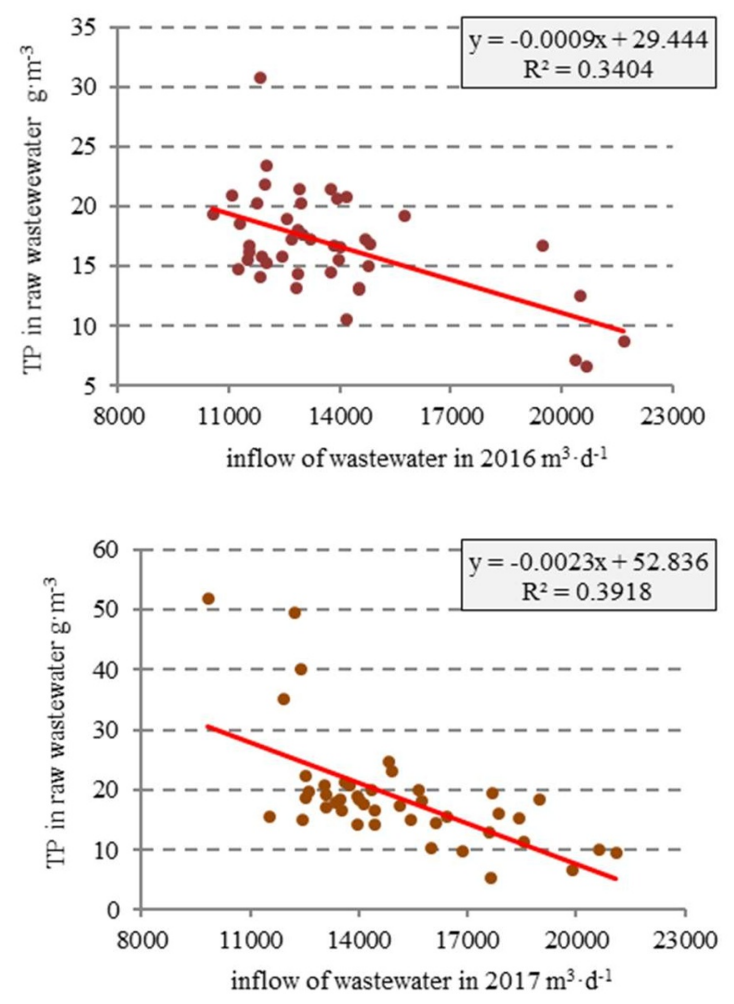

Fig. 4. The influence of the amount of inflow wastewater on Total Phosphorus value in raw wastewater in 2016 and 2017.

In all analyzed cases regarding biogenic indicators, the correlation was at a high level. In the case of the analysis of the influence of the amount of inflowing wastewater on changes in chromium ions $(\mathrm{Cr})$, it was found that the correlation coefficient for the inflow $/ \mathrm{Cr}$ dependence in 2016 was $r_{x, y}=-0.41$, and in 2017 was $r_{x, y}=-0.43$ (Figure 5). In this case, the analysis of the correlation of the impact of the amount of wastewater inflowing to the concentrations of ions of the chromium R2 coefficient of determination explains in 2016 $17.16 \%$ of the model and in $2017-18.20 \%$ of the model. As previously mentioned, the concentrations of chromium ions in the inflowing wastewater are seasonal and this explains the low value of the determination coefficient in this case [12].

For this relation, the correlation coefficient was on an average level. In the case of the dependence of the concentration of chromium ions on the amount of incoming wastewater, a smaller dependence was found than in the case of the influence of the amount of wastewater on changes in the concentration of organic and biogenic indicators. This can be explained by the fact that according to previous studies [12-13], concentrations of chromium ions in wastewater flowing 
into the sewage treatment plant in Nowy Targ occur seasonally, depending on the seasonal functioning of furrier's production facility, which transfer industrial wastewater to the sewage system. The significance of the calculated correlation coefficients was tested with the use of Student's t-test at the significance level of $\alpha=$ 0.05. In all cases, the significance of the examined dependences was stated.
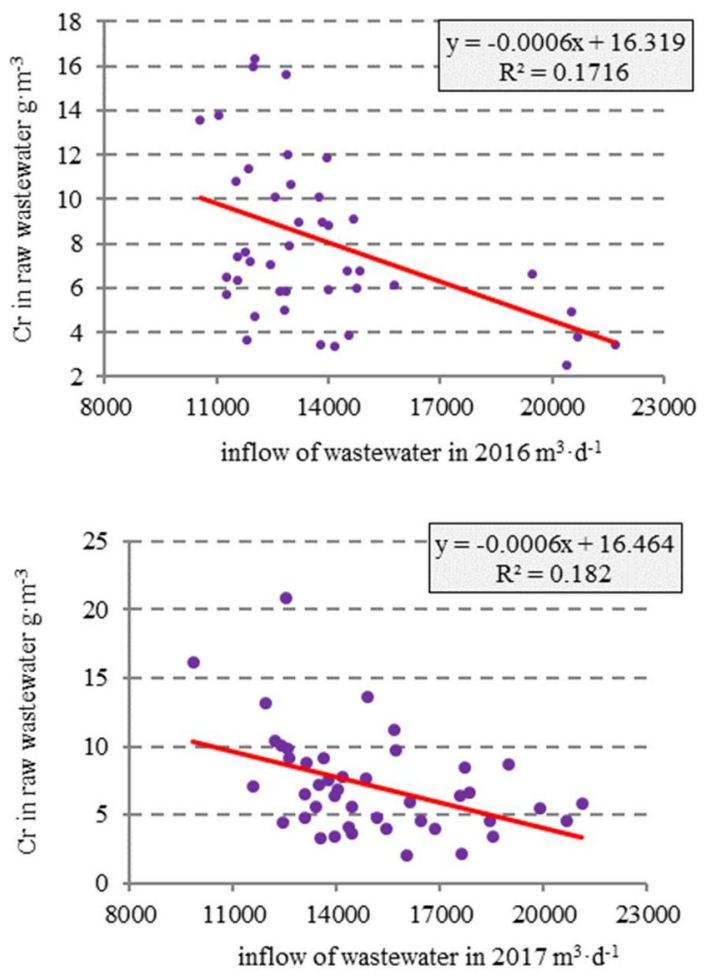

Fig. 5. The influence of the amount of inflow wastewater on Chromium ions $(\mathrm{Cr})$ value in raw wastewater in 2016 and 2017.

Based on the equation of the trend line, it was found that in 2016 with the increase in the amount of inflowing wastewater by $1000 \mathrm{~m}^{3}$, $\mathrm{BOD}_{5}$ values decreased by 34.1 $\mathrm{g} \cdot \mathrm{m}^{-3}$, COD values by $111.7 \mathrm{~g} \cdot \mathrm{m}^{-3}$, total nitrogen concentration by $6.6 \mathrm{~g} \cdot \mathrm{m}^{-3}$, total phosphorus by $0.9 \mathrm{~g} \cdot \mathrm{m}^{-3}$ and the concentration of chromium ions by $0.6 \mathrm{~g} \cdot \mathrm{m}^{-3}$. In 2017, with the increase in the amount of inflowing wastewater by $1000 \mathrm{~m}^{3}, \mathrm{BOD}_{5}$ values decreased by 34.0 $\mathrm{g} \cdot \mathrm{m}^{-3}$, COD values by $94.6 \mathrm{~g} \cdot \mathrm{m}^{-3}$, total nitrogen concentration by $7.2 \mathrm{~g} \cdot \mathrm{m}^{-3}$, total phosphorus by $2.3 \mathrm{~g} \cdot \mathrm{m}^{-3}$ and the concentration of chromium ions by $0.6 \mathrm{~g} \cdot \mathrm{m}^{-3}$.

\section{Conclusion}

Based on the conducted analysis, it was found that the average daily amount of inflowing wastewater to the sewage treatment plant in Nowy Targ was at the level of small and medium diversity. In the analyzed period of two years, the sewage treatment plant was hydraulically loaded at the level of $65.8 \%$ in 2016 and $71.6 \%$ in 2017 - in relation to the flow assumed in the project. The variable amount of inflowing wastewater significantly affects the changes in the concentration of organic and biogenic indicators. Based on the correlation, it was found that the impact on changes in $\mathrm{BOD}_{5}, \mathrm{COD}$, total nitrogen and total phosphorus concentrations is high. In the case of the dependence of the chromium ion concentration $(\mathrm{Cr})$ on the amount of inflowing wastewater, the correlation was found on the average level. In order to prevent the phenomenon of large changes in the concentrations of pollutants in the inflowing wastewater, the sewerage system should be modernized (rebuilt) - from the combined sewer system to the distribution system. Moreover, illegal introduction of rainwater from roof gutters on sewage sections intended for household sewage should be eliminated. Furthermore, measures aimed at elimination of illegally introduced industrial wastewater from furrier's production facility operating in the city of Nowy Targ should be taken.

\section{Acknowledgements}

Publication supported by the Polish Ministry of Science and Higher Education as a part of the program of activities disseminating science from the project „Organization of the First International Science Conference - Ecological and Environmental Engineering”, 26-29 June 2018, Kraków.

\section{References}

1. G. Kaczor, P. Bugajski, Pol. J. Environ. Stud. Vol. 21/2, 381-386 (2012)

2. O. Cieślak, J. Pawełek, Instal, 7-8, 90-95 (2014)

3. A. Wałęga, A. Cupak, J. Pawełek, B. Michalec, Pol. J. Environ. Stud. Vol. 23/3, 909-916 (2014)

4. D. Młyński, K. Chmielowski, A. Młyńska, J. Wat. L. Develop. 28 p. 61-67 (2016)

5. M. Gizińska-Górna, K. Jóźwiakowski, M. Marzec, A. Pytka, B. Sosnowska, M. Różańska-Boczula, A. Listosz, Annual Set The Environ. Protect. 19, 370393 (2017)

6. E. Vaiopoulou, P. Gikas, Water Research, 46, 549 $-570(2012)$

7. E. Arnold, B. Bohm, P.A. Wilderem, Wat. Scien. Tech., 41(1), 115-122 (2000)

8. J. L. Barnard, Materiały seminarium szkoleniowego „Filozofia projektowania a eksploatacja oczyszczalni ścieków" LEM PROJEKT s.c. Kraków, 13-69 (2000)

9. J. L. Barnard, J. A. Oleszkiewicz, Materiały seminarium szkoleniowego „Filozofia projektowania a eksploatacja oczyszczalni ścieków” LEM PROJEKT s.c. Kraków, 239-247 (2000)

10. J. Mucha, Skrypt, Katedra Geologii Kopalnianej, AGH Kraków, 155 (1994) 
11. A. Stanisz, Przystępny kurs statystyki. Tom 1. Wydawnictwo StatSoft Polska Sp. z o.o. Kraków (1998)

12. E. Nowobilska-Majewska, Inż. Ekol., 18(XII) 3035 (2017)

13. P. Bugajski, E. Nowobilska-Majewska, K. Kurek, J. Wat. L. Develop. 35(X-XII), 11-17 (2017) 